\title{
Familial and Genetic Effects on Motor Coordination, Laterality, and Reading-Related Cognition
}

Clyde Francks, D.Phil.

Simon E. Fisher, D.Phil.

Angela J. Marlow, M.Sc.

I. Laurence MacPhie, B.Sc.

Kathleen E. Taylor, D.Phil.

Alex J. Richardson, D.Phil.

John F. Stein, B.M., B.Ch., F.R.C.P.

Anthony P. Monaco, M.D., Ph.D.

\begin{abstract}
Objective: Recent research has provided evidence for a genetically mediated association between language or reading-related cognitive deficits and impaired motor coordination. Other studies have identified relationships between lateralization of hand skill and cognitive abilities. With a large sample, the authors aimed to investigate genetic relationships between measures of reading-related cognition, hand motor skill, and hand skill lateralization.
\end{abstract}

Method: The authors applied univariate and bivariate correlation and familiality analyses to a range of measures. They also performed genomewide linkage analysis of hand motor skill in a subgroup of 195 sibling pairs.

Results: Hand motor skill was significantly familial (maximum heritability= $41 \%$ ), as were reading-related measures. Hand motor skill was weakly but signifi- cantly correlated with reading-related measures, such as nonword reading and irregular word reading. However, these correlations were not significantly familial in nature, and the authors did not observe linkage of hand motor skill to any chromosomal regions implicated in susceptibility to dyslexia. Lateralization of hand skill was not correlated with reading or cognitive ability.

Conclusions: The authors confirmed a relationship between lower motor ability and poor reading performance. However, the genetic effects on motor skill and reading ability appeared to be largely or wholly distinct, suggesting that the correlation between these traits may have arisen from environmental influences. Finally, the authors found no evidence that reading disability and/or low general cognitive ability were associated with ambidexterity.

(Am J Psychiatry 2003; 160:1970-1977)

$\mathrm{D}$ ficulty in learning to read in the absence of any obvious cause, such as low general intelligence, lack of educational opportunity, or overt neurological or sensory handicap (1, 2 ). The condition affects roughly one in 20 school-age children (1). Measures of reading disability are highly heritable $(2,3)$, but the genetic factors underlying this heritable variance are complex and heterogeneous (3-5). Indeed, molecular genetic mapping studies have identified replicable quantitative trait loci contributing to the susceptibility to dyslexia on chromosomes 2,6 , and 18 , as well as several other putative quantitative trait loci (3-6).

In searching for clues to the etiology of dyslexia, researchers have developed numerous cognitive and physiological measures that have been found to correlate with reading measures. Impairments associated with reading disability include a language-related deficit in phonological processing (7) (i.e., an inability to deconstruct words into the component sounds of speech), as well as deficits in learning to read irregularly spelled words $(7,8)$ and the rapid naming of newly presented items (8). The sensory correlates of dyslexia include anomalies in visual (9-11) and auditory (12) processing of rapidly changing stimuli. Differences in regional cortical activation between individuals with dyslexia and comparison subjects have oc- curred during performance of some of these tests $(11,13$, 14). It may be that deficits on one or a subset of such measures can reveal the etiological bases of different subtypes of dyslexia, which currently are diagnosed together as one heterogeneous disorder.

Another clue to an underlying etiology has come from studies that tested for associations between impairments in motor and reading abilities $(15,16)$. These studies were aimed at investigating the role of the cerebellum in implicit or automatized learning of both motor and reading skills (15). Nicolson and colleagues (15) estimated that individuals with dyslexia score approximately -1 standard deviation below comparison subjects on tests of posture, muscle tone, and voluntary movement. Also, postmortem and imaging studies of the cerebellum have identified neuroanatomical, morphological, functional, and biochemical differences between individuals with dyslexia and comparison subjects (15, 17-19).

Wolff and colleagues (20) found that impaired motor coordination co-segregated with dyslexia in roughly half of the families in a clinically recruited sample with reading disability. Wolff (21) proposed that dyslexia with motor impairment constitutes a common and heritable subtype of reading disability. In addition, Bishop (22) found evidence for a common genetic basis for motor immaturity 
and speech and language impairment in twins. Speech and language impairment, like dyslexia, is a heterogeneous disorder with a multifactorial background (23) and is associated with deficits in phonological processing. Literacy problems in children are often accompanied by oral language difficulties and vice versa. Indeed, susceptibility to dyslexia and speech and language impairment may be mediated in part by common genetic influences.

Associations between dyslexia and left-handedness or ambidexterity have also been reported $(24,25)$, although other investigations have not found these associations (26-28). In addition, weak lateralization of hand skill has been reported to associate with low verbal cognitive ability $(29,30)$, but this association has failed to be replicated (31). Nonetheless, handedness is related to asymmetric language dominance, suggesting overlapping genetic and developmental etiologies for handedness and languagerelated cognition (32). Since dyslexia is, in part, a language-related disorder, it is reasonable to test for relations between reading-related cognition and lateralization of hand skill.

We collected a sample of 265 nuclear sibling-pair families, each containing at least one reading-disabled proband, as part of an ongoing molecular genetic study of reading disability $(4,33)$. As well as tests of reading-related and general cognition, all siblings were administered Annett's peg-moving test (34) to derive quantitative measures of hand motor coordination and lateralization of hand skill. A subset of 89 of these families (195 sibling pairs) was genotyped at polymorphic markers spanning the genome to perform linkage analysis of reading-related measures (4). This subset of the group has shown linkage to reading-related measures at loci on chromosomes 6p21.3-23 and 18p11, and both of these quantitative trait loci have been identified in independent samples $(3,5)$. We have also found linkage of relative hand skill (i.e., lefthand versus right-hand) to chromosome 2 p12-q11 in these 195 sibling pairs (28), and we recently replicated this result in an independent sample (35) (not included in the current study).

Our main aims in this study were to test two hypotheses: first, that dyslexia with motor impairment is a common heritable subtype of reading disability $(20,21)$; second, that hand skill lateralization is related to reading ability $(29,31)$. With our group of 641 siblings in 265 families, we performed the largest study to our knowledge aimed at measuring the following:

1. The extent to which hand motor skill and hand skill lateralization are correlated with reading-related measures in a clinically ascertained group with reading disability.

2. The extent to which hand motor skill, hand skill lateralization, reading ability, and verbal/nonverbal reasoning are familial in this group.
3. The extent to which the same familial/genetic effects mediate covariance between different combinations of these measures.

In addition, with our subset of 195 genotyped sibling pairs, we were able to assess whether specific genetic loci mediate any covariance between reading-related and motor measures.

\section{Method}

\section{The Family Group}

We identified 265 unrelated nuclear sibling-pair families through the dyslexia clinic at Royal Berkshire Hospital (33). The majority ( $>90 \%$ ) of the first 200 families were recruited on the basis of 1) having at least one proband whose single-word reading ability was more than 2 standard deviations below that predicted by tests of verbal or nonverbal reasoning $(4,33)$ and 2 ) having evidence of reading disability in one or more siblings of the dyslexic proband (e.g., on the basis of parental reports or school history) $(4,33)$. The majority (roughly $80 \%$ ) of the remaining 65 families were recruited through a minimum of just one reading-disabled proband, with no requirement for reading disability in siblings of the probands. The probands in these families were required to have single-word reading ability of 1 standard deviation or more below that predicted by their age, with a minimum intelligence quotient of 90. All remaining families from either the first 200 families or the final 65 were collected by means of referral to the clinic of at least one reading-disabled proband by a qualified clinician (33). All families were therefore required to contain a minimum of two siblings, at least one of whom was reading disabled. The subjects were given a full description of the experimental procedures, plus the option to ask questions or to withdraw at any time. Written informed consent was then obtained.

We administered a battery of psychometric tests to all available siblings in each family and age-adjusted and standardized their scores against normative control data, as described in previous publications $(4,33)$. These included measures of single-word reading ability, spelling ability, phonological decoding ability (ability to deconstruct written words into phonemic units), phonemic awareness (awareness of the phonemic structure of language), orthographic coding (whole-word recognition), and tests of verbal and nonverbal reasoning.

Blood samples or buccal swabs were donated by all available children and parents for the purpose of genomic DNA extraction (4). The 265 families yielded a total of 641 siblings for whom psychometric test scores and genomic DNA were available (median age $=11.9$ years, range $=5.7$ to 30.6 ). Test scores and genomic DNA were obtained for all probands and at least one sibling in each family. Sibship sizes used in our analyses ranged from two to six (166 with two siblings, 76 with three siblings, 21 with four siblings, one with five siblings, and one with six siblings). The sample consisted uniformly of white Caucasians.

\section{Annett's Peg Test}

We administered Annett's peg-moving test, a well-characterized test of hand motor skill (34), to all 641 siblings in the group. The test involved measuring the time taken by subjects to move, with each hand, a row of pegs on a board from one location to another. Five trials were performed for each hand. These trials yielded mean left- and right- hand times. From these data, we calculated the average time for both hands ([left+right]/2) and regressed this value on age within our group to obtain age-adjusted residual scores. The negative of this residual was used as the variable for hand motor skill, as a measure of age-adjusted hand mo- 
TABLE 1. Reading-Related Cognitive Traits and Motor Skill in 195 Sibling Pairs With At Least One Dyslexic Proband

\begin{tabular}{|c|c|c|c|c|c|c|c|}
\hline \multirow[b]{2}{*}{ Trait } & \multicolumn{7}{|c|}{ Statistic } \\
\hline & Mean & SD & Kurtosis & Skewness & Minimum & Maximum & Number \\
\hline Reading ability & -0.38 & 1.02 & -0.08 & 0.26 & -3.07 & 3.00 & 641 \\
\hline Spelling ability & -0.82 & 0.99 & 0.62 & -0.03 & -3.60 & 3.20 & 630 \\
\hline Orthographic coding & -0.80 & 1.00 & 0.21 & -0.55 & -4.97 & 1.52 & 641 \\
\hline Phonological decoding ability & -0.37 & 0.85 & -0.36 & -0.39 & -2.87 & 1.62 & 652 \\
\hline Phonemic awareness & -0.41 & 0.85 & 0.86 & -0.54 & -3.71 & 2.41 & 628 \\
\hline Verbal reasoning & 1.14 & 0.81 & -0.15 & -0.44 & -1.60 & 3.00 & 638 \\
\hline Nonverbal reasoning & 0.52 & 0.85 & -0.41 & -0.10 & -1.90 & 2.60 & 602 \\
\hline Hand motor skill & 0.00 & 1.00 & -0.43 & -0.69 & -4.05 & 2.45 & 641 \\
\hline Left-hand versus right-hand skill & 0.07 & 0.10 & 0.57 & -0.40 & -0.26 & 0.42 & 641 \\
\hline Degree of skill lateralization & 0.10 & 0.07 & 0.43 & 0.76 & 0.00 & 0.42 & 641 \\
\hline
\end{tabular}

TABLE 2. Maximum Heritability of Reading-Related Cognitive Traits and Motor Skill in 265 Families With At Least One Dyslexic Proband ${ }^{\mathrm{a}}$

\begin{tabular}{lcc}
\hline & $\begin{array}{c}\text { Maximum } \\
\text { Heritability } \\
\text { (twice the sibling } \\
\text { correlation [r] }\end{array}$ & \\
Trait & 0.40 & $\mathrm{p}$ \\
\hline Reading ability & 0.66 & 0.0007 \\
Spelling ability & 0.39 & 0.00001 \\
Orthographic coding & 0.46 & $<0.0007$ \\
Phonological decoding ability & 0.52 & $<0.000001$ \\
Phonemic awareness & 0.83 & $<0.00001$ \\
Verbal reasoning & 0.42 & 0.0003 \\
Nonverbal reasoning & 0.41 & 0.0005 \\
Hand motor skill & 0.23 & 0.03 \\
Left-hand versus right-hand skill & 0.04 & 0.36 \\
Degree of skill lateralization &
\end{tabular}

a Based on 20 random samplings of one sibling pair from each family.

tor skill. We also derived the difference between hands, adjusted for overall hand skill, as a measure of relative (left versus right) hand skill for each child (28), which was calculated as (left-right) / ([left+right]/2). Finally, as a measure of the degree of hand skill lateralization in either direction, we used the unsigned magnitude of this measure.

\section{Univariate Familiality Analysis}

Pearson correlation coefficients between sibling scores were calculated for individual measures. For sibling data, twice the correlation coefficients yields a maximum estimate for trait heritability (i.e., the proportion of trait variance caused by genetic factors). Some proportion of sibling covariance may also be due to sibling-shared environmental effects. Since many of the sibships contained more than two individuals, not all sibling pairs were independent for the purposes of these analyses. We therefore performed 20 random samplings of one sibling pair from each of the 265 families and derived mean univariate familiality estimates. Significance tests were one-tailed.

\section{Bivariate Correlation Analysis}

Bivariate Pearson correlations between measures were calculated to assess overall trait relationships. We performed 20 random samplings of one child from each of the 265 families and obtained mean intertrait correlation coefficients. We used onetailed tests of significance to test the hypothesis that inferior hand motor skill is associated with impaired reading ability. Likewise, we used one-tailed tests to assess whether relatively superior lefthand skill or a lower degree of lateralization was associated with impaired reading ability.

\section{Bivariate Familiality Analysis}

We performed 20 random samplings of one sibling pair from each of the 265 families and obtained mean cross-sibling inter- trait correlation coefficients to measure the extent to which the same familial factors were responsible for covariance between different measures. Again, one-tailed tests of significance were used.

\section{Genotyping}

All available individuals from the first 89 families of the group were genotyped for over 400 polymorphic microsatellite markers spanning the genome, according to standard protocols (4). This allowed multipoint identity-by-descent sharing at all points across the genome to be measured for all 195 sibling pairs in these families. For genetic marker maps, we used supplemented versions of version 2.0 of Sex Averaged CHLC/ABI Prism Maps (http://www. well.ox.ac.uk/ simon/dyslexia/dys_genscan.shtml).

\section{Linkage Analysis}

Genomewide linkage analysis of hand motor skill was performed by using Haseman-Elston regression with Genehunter 2.0 (http://www-genome.wi.mit.edu/ftp/distribution/software/ genehunter/gh2) or Mapmaker/Sibs 2.0 for the X chromosome (http://www-genome.wi.mit.edu/ftp/distribution/software/ sibs). In all instances, we used the "all pairs, unweighted" options, which we have found in simulation studies to best approximate the theoretically derived significance distributions for linkage statistics in this sibling group (4).

\section{Results}

\section{Descriptive Statistics}

Table 1 shows descriptive statistics for all variables. All cognitive variables are given as z scores, standardized against normative data (33). Owing to a lack of raw normative data for peg moving, the variable hand motor skill was standardized within our study group, and left-hand versus right-hand skill and left-hand versus right-hand skill lateralization are presented as unstandardized $(28,35)$. The means for all reading-related measures were negative, as expected (means between -0.37 and -0.93 SD). However, each of the reading-related measures showed relatively undiminished variance (standard deviations between 0.85 and 1.02), which presumably arose because of the recruitment of unselected siblings in addition to dyslexic probands (33) and because most measures were imperfectly correlated with the measures that were used for recruitment. The mean (left-hand versus right-hand skill) was similar to that derived from normative data (34) (group mean $=0.070$, normative mean $=0.072$ ). This suggests that the group could be considered unselected for degree of 
TABLE 3. Correlations Among Reading-Related Cognitive Abilities and Motor Skill in 265 Families With At Least One Dyslexic Proband ${ }^{\mathrm{a}}$

\begin{tabular}{|c|c|c|c|c|c|c|c|c|c|c|c|c|c|c|c|c|}
\hline \multirow[b]{2}{*}{ Trait } & \multicolumn{2}{|c|}{$\begin{array}{l}\text { Reading } \\
\text { Ability }\end{array}$} & \multicolumn{2}{|c|}{$\begin{array}{l}\text { Spelling } \\
\text { Ability }\end{array}$} & \multicolumn{2}{|c|}{$\begin{array}{l}\text { Orthographic } \\
\text { Coding }\end{array}$} & \multicolumn{2}{|c|}{$\begin{array}{c}\text { Phonological } \\
\text { Decoding } \\
\text { Ability }\end{array}$} & \multicolumn{2}{|c|}{$\begin{array}{l}\text { Phonemic } \\
\text { Awareness }\end{array}$} & \multicolumn{2}{|c|}{$\begin{array}{c}\text { Verbal } \\
\text { Reasoning }\end{array}$} & \multicolumn{2}{|c|}{$\begin{array}{l}\text { Nonverbal } \\
\text { Reasoning }\end{array}$} & \multicolumn{2}{|c|}{$\begin{array}{l}\text { Hand Motor } \\
\text { Skill }\end{array}$} \\
\hline & $r$ & $\mathrm{p}$ & $r$ & $\mathrm{p}$ & $r$ & $\mathrm{p}$ & $r$ & $\mathrm{p}$ & $r$ & $\mathrm{p}$ & $r$ & $\mathrm{p}$ & $r$ & $\mathrm{p}$ & $r$ & $\mathrm{p}$ \\
\hline Spelling ability & 0.19 & $<0.002$ & & & & & & & & & & & & & & \\
\hline Orthographic coding & 0.18 & 0.003 & 0.19 & 0.001 & & & & & & & & & & & & \\
\hline Phonological decoding & & & & & & & & & & & & & & & & \\
\hline $\begin{array}{l}\text { ability } \\
\text { Phonemic awareness }\end{array}$ & $\begin{array}{l}0.16 \\
0.18\end{array}$ & 0.006 & $<0.15$ & 0.008 & 0.14 & $<0.02$ & & & & & & & & & & \\
\hline Phonemic awareness & 0.18 & 0.002 & 0.19 & 0.002 & 0.17 & 0.004 & 0.16 & 0.006 & & & & & & & & \\
\hline Verbal reasoning & 0.15 & 0.008 & 0.06 & 0.18 & 0.13 & 0.02 & 0.09 & 0.08 & 0.11 & 0.04 & & & & & & \\
\hline Nonverbal reasoning & 0.12 & 0.03 & 0.09 & $<0.09$ & 0.11 & 0.04 & 0.11 & 0.04 & 0.11 & 0.04 & 0.17 & 0.004 & & & & \\
\hline Hand motor skill & -0.01 & 0.46 & 0.05 & 0.21 & -0.02 & 0.38 & -0.01 & 0.46 & 0.01 & 0.44 & 0.00 & 0.48 & 0.08 & 0.09 & & \\
\hline Left-hand versus & & & & & & & & & & & & & & & & \\
\hline right-hand skill & -0.02 & 0.37 & 0.02 & 0.36 & 0.00 & 0.50 & -0.04 & 0.25 & -0.07 & 0.12 & 0.01 & 0.46 & -0.01 & 0.45 & 0.09 & 0.07 \\
\hline Degree of skill & & & & & & & & & & & & & & & & \\
\hline lateralization & -0.01 & 0.46 & 0.05 & 0.22 & 0.00 & 0.48 & 0.07 & 0.14 & -0.09 & 0.08 & 0.01 & 0.46 & -0.01 & 0.43 & -0.04 & 0.26 \\
\hline
\end{tabular}

skill lateralization or handedness (28). Finally, males were overrepresented among probands (65\% of the probands were male), which is typical of clinical reading disability samples (33). Therefore, although gender did show significant associations with reading-related measures (data not shown), our group was unsuitable for an unbiased investigation of gender effects.

\section{Univariate Familialities}

All of the variables were significantly familial, apart from the absolute magnitude of hand skill lateralization (to left or right) (Table 2). Maximum heritabilities of cognitive variables were between $39 \%$ and $83 \%$ (all $\mathrm{p}<0.0007$ ), consistent with findings from twin studies. The maximum heritability of left-hand versus right-hand skill was $23 \%$ $(\mathrm{p}<0.03)$, consistent with our prior analyses of subsets of the total group (28). The measure of hand motor skill had a maximum heritability of $41 \%(\mathrm{p}=0.0005)$, suggesting a substantial genetic variance component. The familiality of hand motor skill indicated that the pegboard test was sufficiently sensitive to reliably detect and quantify familial factors influencing hand motor skill.

\section{Bivariate Correlations}

All bivariate correlations between reading-related measures were strong and significant, consistent with results from previous studies (Table 3 ) $(\mathrm{r}=0.38-0.78$, all $\mathrm{p}<0.0001)$. Verbal reasoning and nonverbal reasoning were less strongly, but still significantly, correlated with all readingrelated measures $(\mathrm{F}=0.170 .40$, all $\mathrm{p}<0.005)$. Hand motor skill was weakly but significantly correlated with several reading-related measures $(\mathrm{r}=0.12-0.17, \mathrm{p}<0.003-0.04)$, such that poor reading performance was associated with slower peg moving. This finding was consistent with results obtained by Nicolson and colleagues (15), although the correlation was not as high as might have been predicted from their studies. However, hand motor skill was not significantly correlated with verbal reasoning or nonverbal reasoning, in contrast to results reported by Leask and Crow (30), who found significant correlations be- tween hand motor skill and measures of verbal and nonverbal cognitive ability. Lateralized relative hand skill (left versus right) was not significantly correlated with any cognitive measure, and neither was the magnitude of hand skill lateralization to the left or right.

\section{Bivariate Familiality Analysis}

Cross-sibling intertrait correlation analyses yield a maximum estimate of the degree to which the same genetic factors influence a pair of correlated variables. These are presented in Table 4. The majority of these correlations for pairs of reading-related and cognitive measures showed significant evidence for common familial influences, again consistent with data from twin studies ( $\mathrm{r}=0.11-0.19$, $\mathrm{p}>0.05-0.001$ ). However, despite the strong univariate familiality of hand motor skill ( $\mathrm{r}=0.21, \mathrm{p}=0.0005)$, the strong univariate familialities of reading-related measures $(r=$ $0.20-0.33$, all $\mathrm{p}<0.0008$ ), and the significant correlations between hand motor skill and some reading-related measures $(\mathrm{r}=0.12-0.17)$, hand motor skill showed no significant evidence for shared familial influences with any reading-related measure. For a power comparison, notice that the overall correlations of nonverbal intelligence with phonological decoding ability and phonemic awareness (measures of phonological processing ability) were both 0.17 (Table 3), a value that was equal to the overall correlation of hand motor skill with phonological decoding ability. Furthermore, the univariate maximum heritabilities of nonverbal reasoning and hand motor skill were similar (nonverbal reasoning $=42 \%$, hand motor skill $=41 \%$ ). However, in bivariate familiality analysis (Table 4), nonverbal reasoning showed significant evidence for shared familial influences with phonological decoding ability and phonemic awareness (both $\mathrm{r}=0.11$ and $\mathrm{p}<0.05$ ), whereas there was not even a suggestion of shared familial influences between hand motor skill and phonological decoding ability $(\mathrm{r}=-0.01, \mathrm{p}=0.46)$. This comparison confirms that our group provided sufficient power to detect bivariate familial effects for pairs of traits with overall correlations as low 
TABLE 4. Cross-Sibling Bivariate Correlations Among Reading-Related Cognitive Abilities and Motor Skill in 265 Families With At Least One Dyslexic Proband ${ }^{\mathrm{a}}$

\begin{tabular}{|c|c|c|c|c|c|c|c|c|c|c|}
\hline \multirow[b]{2}{*}{ Trait } & \multicolumn{2}{|c|}{$\begin{array}{l}\text { Reading } \\
\text { Ability }\end{array}$} & \multicolumn{2}{|c|}{$\begin{array}{l}\text { Spelling } \\
\text { Ability }\end{array}$} & \multicolumn{2}{|c|}{$\begin{array}{l}\text { Orthographic } \\
\text { Coding }\end{array}$} & \multicolumn{2}{|c|}{$\begin{array}{c}\text { Phonological } \\
\text { Decoding } \\
\text { Ability }\end{array}$} & \multicolumn{2}{|c|}{$\begin{array}{l}\text { Phonemic } \\
\text { Awareness }\end{array}$} \\
\hline & $r$ & $\mathrm{p}$ & $r$ & $\mathrm{p}$ & $r$ & $\mathrm{p}$ & $r$ & $\mathrm{p}$ & $r$ & $\mathrm{p}$ \\
\hline Spelling ability & 0.71 & $<0.0001$ & & & & & & & & \\
\hline Orthographic coding & 0.78 & $<0.0001$ & 0.63 & $<0.0001$ & & & & & & \\
\hline Phonological decoding ability & 0.65 & $<0.0001$ & 0.51 & $<0.0001$ & 0.64 & $<0.0001$ & & & & \\
\hline Phonemic awareness & 0.54 & $<0.0001$ & 0.52 & $<0.0001$ & 0.60 & $<0.0001$ & 0.59 & $<0.0001$ & & \\
\hline Verbal reasoning & 0.40 & $<0.0001$ & 0.26 & $<0.0001$ & 0.32 & $<0.0001$ & 0.29 & $<0.0001$ & 0.29 & $<0.0001$ \\
\hline Nonverbal reasoning & 0.29 & $<0.0001$ & 0.32 & $<0.0001$ & 0.17 & $<0.005$ & 0.17 & $<0.004$ & 0.24 & 0.0001 \\
\hline Hand motor skill & 0.09 & $<0.08$ & 0.07 & 0.12 & 0.14 & $<0.02$ & 0.17 & $<0.003$ & 0.12 & $<0.04$ \\
\hline Left-hand versus right-hand skill & -0.05 & 0.23 & -0.05 & 0.22 & -0.04 & 0.28 & -0.06 & 0.16 & -0.07 & 0.13 \\
\hline Degree of skill lateralization & -0.05 & 0.20 & 0.0 & 0.49 & -0.01 & 0.43 & -0.04 & 0.27 & -0.05 & 0.21 \\
\hline
\end{tabular}

a Based on 20 random samplings of one sibling pair from each family.

FIGURE 1. Genomewide Linkage Screen for Hand Motor Skill in 195 Sibling Pairs $^{a}$

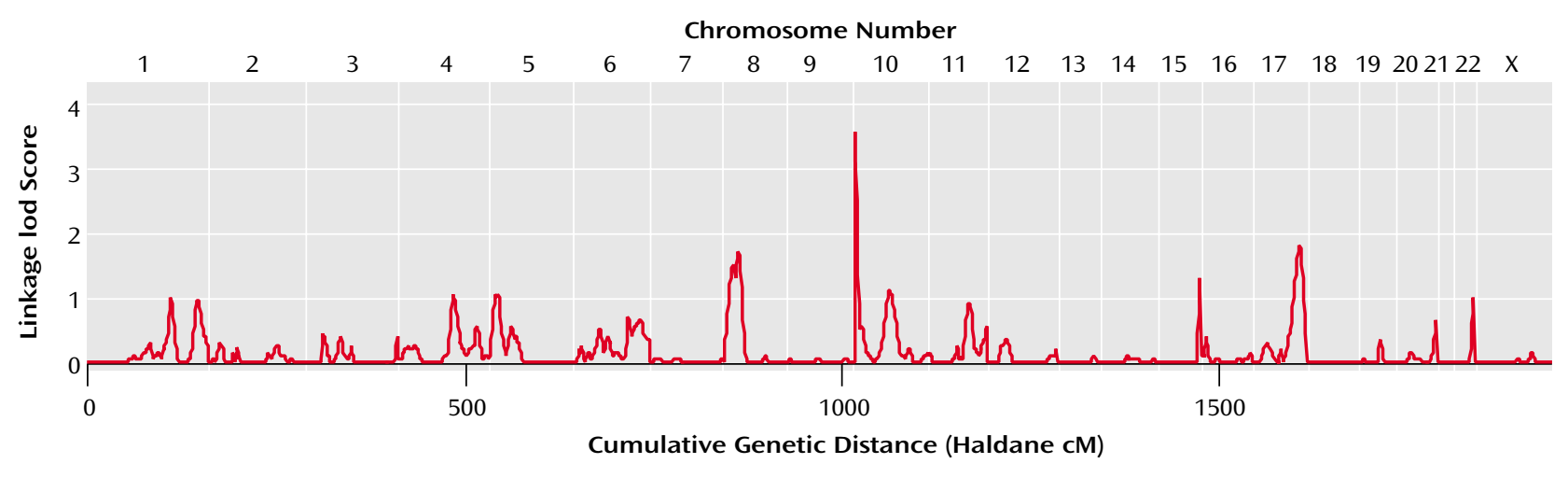

${ }^{a}$ Chromosomes are represented from p-telomere (left) to q-telomere (right).

as 0.17 but that no detectable shared familial effects existed between hand motor skill and phonological decoding ability nor between hand motor skill and any other reading-related measure.

Neither relative left- versus right-hand skill nor its unsigned magnitude, showed any familial correlation with reading-related or cognitive measures (Table 4), but this was unsurprising, since neither measure showed any overall correlation with reading-related or cognitive measures (Table 3).

\section{Genomewide Linkage Screen}

Results from genomewide linkage analysis of hand motor skill in 195 sibling pairs are shown in Figure 1. No linkage lod scores over 2 were found, which could have been suggestive of linkage (36), apart from the peak at marker D10S249 on 10ptel (covering the roughly 4.5 megabases at the $10 \mathrm{p}$ telomere), which yielded $\mathrm{LOD}=3.55$ (point-wise $\mathrm{p}=$ 0.00003 ). This quantitative trait locus nearly surpassed the $\mathrm{p}=0.00002$ threshold for genomewide significance proposed by Lander and Kruglyak (36). Although linkages at telomeric locations may arise in part from reduced multipoint information, this quantitative trait locus is nonetheless, to our knowledge, the first to be reported for a motor measure in the normal range of ability.
No suggestive linkages of hand motor skill were observed to any of the regions that have shown linkage to reading-related measures in this group (in particular loci on chromosomes 6 and 18) (4) or that have shown linkage to reading disability in other studies (including loci on chromosomes 1, 2, 3, 6, 15 and 18) $(3,5)$.

Finally, hand motor skill showed no linkage to 2p12-q11, a locus that has shown linkage to left-hand versus righthand skill in this group (28) and in an independent sample (35). This is consistent with the low nonsignificant correlation between left- versus right-hand skill and overall hand motor skill ( $\mathrm{r}=0.02, \mathrm{p}=0.39)$.

\section{Discussion}

In this study, we analyzed familial and genetic relationships between measures of reading-related and cognitive abilities, hand motor skill, and hand skill lateralization in the largest study of its kind to date (641 siblings in 265 independent nuclear families). The families were recruited through reading-disabled probands, but the group also included many unselected siblings, and this, together with the use of a broad battery of reading-related measures, ensured that all reading-related variables contained sufficient variance to perform powerful quantitative correlation and familiality analyses within this group. 


\begin{tabular}{|c|c|c|}
\hline $\begin{array}{c}\text { Verbal } \\
\text { Reasoning }\end{array}$ & $\begin{array}{l}\text { Nonverbal } \\
\text { Reasoning }\end{array}$ & $\begin{array}{l}\text { Hand Motor } \\
\text { Skill }\end{array}$ \\
\hline$p$ & $p$ & $r$ \\
\hline
\end{tabular}

\begin{tabular}{rcrrrr}
0.30 & $<0.0001$ & & & & \\
0.05 & 0.23 & 0.03 & 0.35 & & \\
0.03 & 0.31 & 0.04 & 0.29 & 0.02 & 0.39 \\
-0.04 & 0.26 & -0.05 & 0.23 & 0.07 & 0.12 \\
\hline
\end{tabular}

Our study was designed to investigate two etiological hypotheses for dyslexia. One hypothesis was that an inherited disorder of cerebellar function is a common cause of reading disability $(16,20-22)$ and predicted that dyslexia will be associated with inherited generalized motor impairment. The second hypothesis was that a disruption of lateralized cerebral development, affecting the neuroanatomical substrates of language-related cognition, is a common cause of dyslexia $(24,29)$. Since handedness is associated with hemispheric language dominance, this second hypothesis predicted that hand skill lateralization might show correlations with reading and/or language-related measures.

\section{Reading Ability and Hand Motor Skill}

All of our reading-related and cognitive measures were found to be significantly familial, consistent with results from twin studies that have shown significant heritabilities for these or closely related measures. Hand motor skill was also moderately familial, which suggests that a substantial genetic effect influences this trait. However, despite weak correlations between hand motor skill and some reading-related measures, there was no evidence that the same familial or genetic effects influenced variability in hand motor skill and reading ability in our group. The lack of evidence for a common genetic effect on these traits was found in our cross-sibling bivariate correlation analysis and also in the linkage analysis, which did not identify any genomic region showing suggestive linkage to both hand motor skill and reading-related measures.

The correlations between reading-related measures and hand motor skill that we found (correlations up to $\mathrm{r}=0.17$ ) yielded sufficient power to detect substantial common genetic effects on these traits had such effects been present. The possibility remains that a weak common genetic effect on hand motor skill and reading ability was present in our group. Nonetheless, our results indicate that the genetic effects on both motor coordination and reading ability are, while individually strong, mostly or wholly distinct from one another.
In the absence of evidence for common genetic effects on motor and reading abilities, the correlations between hand motor skill and reading-related measures in our siblings may presumably have arisen by means of nonfamilial environmental mechanisms. If then, as proposed (20, 21), a disruption of cerebellar function underlies susceptibility to one common subtype of reading disability, it may make sense for researchers who are aiming to identify the biological causes of "cerebellar dyslexia" to focus efforts on environmental, possibly in utero, mechanisms rather than on classical genetic effects. Alternatively, the correlations that we observed may have been a reflection of overall performance during the test battery (for example, arising from individual differences in attention or fatigue during the test sessions).

A model in which reading and motor coordination have strong, independent familial variance but are also intercorrelated is partly consistent with the findings of Wolff and colleagues (20), who observed co-segregation of reading and motor impairments in families with at least two members with reading disability. However, independent familial effects on reading and motor measures would not explain the high prevalence of motor impairments among the reading-disabled probands of Wolff and colleagues (20) (roughly half of their probands) nor the degree of cosegregation between reading and motor impairment that they observed. It may be that the sample of Wolff and colleagues (20) was enriched for a subtype of familial dyslexia with motor impairment for a reason related to their study group recruitment. Equally, familial dyslexia with motor impairment may have been underrepresented in our own study group. It should also be noted that we relied on a single measure of motor ability for our analyses, since the collection of such measures was not a primary aim of our original reading disability study design $(4,33)$. Nonetheless, our motor measure was sufficiently sensitive to detect substantial familial effects and also to reveal a correlation with reading-related measures.

\section{Linkage Screen for Hand Motor Skill}

The genomewide linkage screen for motor skill that we used was the first of its kind, to our knowledge. The screen identified a putative quantitative trait locus for hand motor skill near the chromosome 10 ptelomere. Although we did not identify a common genetic effect on motor skill and reading ability in our study, the possibility remains that variation in motor skill is related to language-related cognitive deficits in speech and language impairment (22). However, we did not observe linkage to the loci that were implicated in susceptibility to speech and language impairment by the first genomewide screen for this disorder (23). Nonetheless, motor skill may be of relevance to other neuropsychiatric conditions as an endophenotype, and further investigation of the quantitative trait locus for motor skill on chromosome 10ptel may therefore yield insights into the etiologies of such conditions. 


\section{Cognition and Laterality}

Lateralized relative hand skill (i.e., a quantitative measure of handedness) was significantly familial in our group, consistent with previous findings based on subsets of the total current group (28). This was also consistent with our finding of at least one replicated quantitative trait locus for this trait $(28,35)$. However, lateralized relative hand skill showed no significant correlation with readingrelated or cognitive measures; neither did the magnitude of hand skill lateralization to left or right (which, in addition, showed no significant evidence for familial effects). Leask and Crow (30) reported an association between verbal and nonverbal cognitive abilities and the absolute magnitude of hand skill lateralization, but our findings were consistent with those of Mayringer and Wimmer (31), who failed to identify this relationship. It should be noted, however, that the sample studied by Leask and Crow (30) comprised roughly 13,000 individuals, whereas our study, like that of Mayringer and Wimmer (31), was performed using data from just hundreds of individuals and with different cognitive tests. Therefore, our results cannot exclude a subtle relationship between hand skill lateralization and cognitive abilities, especially given that handedness and lateralized cognition are known to be developmentally related (32).

\section{Summary}

In summary, we have evidence, from familial and molecular genetic analysis of a large group with reading disability, that dyslexia with impaired motor coordination is not a common heritable subtype of reading disability. The familial effects on motor coordination and reading ability were found to be individually strong but largely or wholly distinct. Nonetheless, we found a moderate correlation between motor and reading abilities that was at least consistent with previous studies that have identified this relationship $(15,20)$. This finding lends support to the hypothesis that one subtype of dyslexia may be caused by a neurological disruption of cerebellar function (15). However, our data suggest that such a disruption may not be genetically mediated and is perhaps not an important aspect of reading disability in most clinical cases. Finally, our data do not support a relationship between variation in reading or cognitive abilities and lateralization of hand skill.

Received Jan. 7, 2003; revision received May 27, 2003; accepted June 6, 2003. From the Wellcome Trust Centre for Human Genetics and the Department of Physiology, University of Oxford. Address reprint requests to Dr. Monaco, Wellcome Trust Centre for Human Genetics, University of Oxford, Roosevelt Drive, Oxford, UK; anthony.monaco@well.ox.ac.uk (e-mail).

Collection of the family group and genotyping were funded by the Wellcome Trust. Mr. MacPhie is funded by the British Council and the National Sciences and Engineering Research Council of Canada. Dr. Fisher is a Royal Society Research Fellow, and Dr. Monaco is a Wellcome Trust Principal Research Fellow.

The authors thank the families that participated in this study; Janet Walter, Pam Southcott, Sue Fowler, and Chris Clisby for data collection and testing; Dianne Newbury, Yumiko Ishikawa-Brush, Helene
Rees, and Joanne Smith for assistance with genotyping; and Joel Talcott, Eva Cyhlarova, and Catherine Stoodley for providing useful background information.

\section{References}

1. Smith SD, Gilger JW, Pennington BF: Dyslexia and other specific learning disorders, in Principles and Practice of Medical Genetics. Edited by Rimoin DL, Connor JM, Pyeritz RE. New York, Churchill Livingston, 1996, pp 1767-1789

2. DeFries JC, Fulker DW, LaBuda MC: Evidence for a genetic aetiology in reading disability of twins. Nature 1987; 329:537-539

3. Fisher SE, DeFries JC: Developmental dyslexia: genetic dissection of a complex cognitive trait. Nature Rev Neurosci 2002; 3: 767-780

4. Fisher SE, Francks C, Marlow AJ, MacPhie IL, Newbury DF, Cardon LR, Ishikawa-Brush Y, Richardson AJ, Talcott JB, Gayán J, Olson RK, Pennington BF, Smith SD, DeFries JC, Stein JF, Monaco AP: Independent genome-wide scans identify a chromosome 18 quantitative-trait locus influencing dyslexia. Nat Genet 2002; 30:86-91

5. Francks C, MacPhie IL, Monaco AP: The genetic basis of dyslexia. Lancet Neurol 2002; 1:483-490

6. Fisher SE, Marlow AJ, Lamb J, Maestrini E, Williams DF, Richardson AJ, Weeks DE, Stein JF, Monaco AP: A quantitative-trait locus on chromosome $6 p$ influences different aspects of developmental dyslexia. Am J Hum Genet 1999; 64:146-156

7. Castles A, Coltheart M: Varieties of developmental dyslexia. Cognition 1993; 47:149-180

8. Olson RK, Datta H, Gayan J, DeFries JC: A behavioral-genetic analysis of reading disabilities and component processes, in Converging Methods for Understanding Reading and Dyslexia. Edited by Klein RM, McMullen PA. Cambridge, Mass, MIT Press, 1999, pp 133-151

9. Stein J, Walsh V: To see but not to read: the magnocellular theory of dyslexia. Trends Neurosci 1997; 20:147-152

10. Stein JF, Richardson AJ, Fowler MS: Monocular occlusion can improve binocular control and reading in dyslexics. Brain 2000; 123:164-170

11. Eden GF, VanMeter JW, Rumsey JM, Maisog JM, Woods RP, Zeffiro TA: Abnormal processing of visual motion in dyslexia revealed by functional brain imaging. Nature 1996; 382:66-69

12. Tallal P: Auditory temporal perception, phonics and reading disabilities in children. Brain Lang 1980; 9:182-192

13. Rumsey JM, Nace K, Donohue B, Wise D, Maisog JM, Andreason $\mathrm{P}$ : A positron emission tomographic study of impaired word recognition and phonological processing in dyslexic men. Arch Neurol 1997; 54:562-573

14. Paulesu E, Demonet JF, Fazio F, McCrory E, Chanoine V, Brunswick N, Cappa SF, Cossu G, Habib M, Frith CD, Frith U: Dyslexia: cultural diversity and biological unity. Science 2001; 291:21652167

15. Nicolson RI, Fawcett AJ, Dean P: Developmental dyslexia: the cerebellar hypothesis. Trends Neurosci 2001; 24:508-511

16. Bishop DVM: Cerebellar abnormalities in developmental dyslexia: cause, correlate, or consequence? Cortex 2002; 38:491498

17. Rae C, Lee MA, Dixon RM, Blamire AM, Thompson CH, Styles P, Talcott J, Richardson AJ, Stein JF: Metabolic abnormalities in developmental dyslexia detected by $1^{\mathrm{H}}$ magnetic resonance spectroscopy. Lancet 1998; 351:1849-1852

18. Rae C, Harasty J, Dzendrowskyj TE, Talcott JB, Simpson JM, Blamire AM, Dixon RM, Lee MA, Thompson CH, Styles P, Richardson AJ, Stein JF: Cerebellar morphology in developmental dyslexia. Neuropsychologia 2002; 40:1295-1297 
19. Finch AJ, Nicolson RI, Fawcett AJ: Evidence for a neuroanatomical difference within the olivo-cerebellar pathway of adults with dyslexia. Cortex 2002; 38:529-539

20. Wolff PH, Melngailas I, Obregon M, Bedrosian M: Family patterns of developmental dyslexia, part II: behavioral phenotypes. Am J Med Genet 1995; 60:494-505

21. Wolff PH: A candidate phenotype for familial dyslexia. Eur Child Adolesc Psychiatry 1999; 8(suppl 3):21-27

22. Bishop DVM: Motor immaturity and specific speech and language impairment: evidence for a common genetic basis. Am J Med Genet 2001; 114:56-63

23. SLI Consortium: a genomewide scan identifies two novel loci involved in specific language impairment. Am J Hum Genet 2002; 70:384-398

24. Geschwind N, Behan P: Left-handedness: association with immune disorder, migraine, and developmental learning disorder. Proc Natl Acad Sci USA 1982; 79:5097-5100

25. Tønnesen FE, Løkken MA, Høien T, Lundberg I: Dyslexia, lefthandedness, and immune disorders. Arch Neurol 1993; 50: 411-416

26. Pennington BF, Smith SD, Kimberling WJ, Green PA, Haith MM: Left-handedness and immune disorders in familial dyslexics. Arch Neurol 1987; 44:634-639

27. Gilger JW, Pennington BF, Green P, Smith SM, Smith SD: Reading disability, immune disorders and non-right-handedness: twin and family studies of their relations. Neuropsychologia 1992; 30:209-227
28. Francks C, Fisher SE, MacPhie IL, Richardson AJ, Marlow AJ, Stein JF, Monaco AP: A genomewide linkage screen for relative hand skill in sibling pairs. Am J Hum Genet 2002; 70:800-805

29. Crow TJ, Crow LR, Done DJ, Leask S: Relative hand skill predicts academic ability: global deficits at the point of hemispheric indecision. Neuropsychologia 1998; 36:1275-1282

30. Leask SJ, Crow TJ: Word acquisition reflects lateralization of hand skill. Trends Cogn Sci 2001; 5:513-516

31. Mayringer $\mathrm{H}$, Wimmer $\mathrm{H}$ : No deficits at the point of hemispheric indecision. Neuropsychologia 2002; 40:701-704

32. Geschwind DH, Miller BL, DeCarli C, Carmelli D: Heritability of lobar brain volumes in twins supports genetic models of cerebral laterality and handedness. Proc Natl Acad Sci USA 2002; 99:3176-3181

33. Marlow AJ, Fisher SE, Richardson AJ, Francks C, Talcott JB, Monaco AP, Stein JF, Cardon LR: Investigation of quantitative measures related to reading disability in a large sample of sib-pairs from the UK. Behav Genet 2001; 31:219-230

34. Annett M: Left, Right, Hand and Brain: The Right Shift Theory. London, Lawrence Erlbaum Associates, 1985

35. Francks C, DeLisi LE, Fisher SE, Laval SH, Rue JE, Stein JF, Crow TJ, Monaco AP: Confirmatory evidence for linkage of relative hand skill to 2p12-q11 (letter). Am J Hum Genet 2003; 72:499502

36. Lander E, Kruglyak L: Genetic dissection of complex traits: guidelines for interpreting and reporting linkage results. Nat Genet 1995; 11:241-247 